\title{
Stock Returns, Term Structure, Inflation and Real Activity: An International Perspective
}

\author{
Fabio Canova * \\ Department of Economics, Universitat Pompeu Fabra, \\ Trias Fargas 25-27, E-08005, Barcelona, Spain, \\ Dipartimento di Economia, Universita' di Modena, \\ Corso Berengario 51, I-41100 Modena, Italy; \\ and \\ CEPR \\ and \\ Gianni De Nicoló \\ Department of Economics, Brandeis University \\ Waltham, MA, 02254-9110, USA; \\ This Draft, January 1997
}

\begin{abstract}
This paper analyses the empirical interdependences among asset returns, real activity and inflation from a multicountry and international point of view. We find that nominal stock returns are significantly related to inflation only in the US, that the US term structure of interest rates predicts both domestic and foreign inflation rates while foreign term structures do not have this predictive power and that innovations in inflation and exchange rates induce insignificant responses of real and financial variables. An interpretation of the dynamics and some policy implications of the results are provided.
\end{abstract}

JEL Classification nos: C15, E43.

Key Words: Transmission, Business Cycles, International Stock Returns, Financial Markets.

*We would like to thank M. Evans, B. Gerard, G. Hardouvelis, A. Weber, M. Wickens and the participants of seminars at UPF, the CEPR workshop on Monetary Policy in Europe, the UK Macro Money workshop and the 23rd European Finance Association annual meetings for comments and suggestions. Canova acknowledges the financial support of DGICYT and CNR grants. 


\section{Introduction}

The relationship among asset returns, real activity and inflation is at the center stage of the research agenda of financial economists (see e.g. Fama (1981) and (1990b) or Harvey (1988)), and of those branches of the macroeconomic literature attempting to reconcile modern business cycle theory with empirical financial market regularities (see Cochrane and Hansen (1992), Danthine and Donaldson (1995), Boldrin, Christiano and Fisher (1995)) and to assess the real effects of monetary policy (see e.g. Sims (1992), Bernanke and Blinder (1992) or Gordon and Leeper (1994)). Yet, the empirical evidence regarding the dynamic interaction among these variables is incomplete in at least two respects: it is available primarily for the US and it concerns domestic variables taken in isolation from the rest of the world. By contrast, recent developments in the world economy are marked by the relative decline of the importance of the US economy and by the fast pace of integration of the real, financial and monetary sides of industrialized countries.

In this paper we analyze the empirical interdependences among asset returns, real activity and inflation from a multicountry and international point of view. Our goal is twofold. First, we aim at assessing the robustness of some of the empirical regularities found in the US. Second, we investigate how shocks generated in various markets are propagated to the world economy. This may allow, on one hand, to sort out the type of shock more likely to be the impulse and the links responsible for the international propagation of domestic disturbances and, on the other, to study whether there are cross country heterogeneities both in terms of responsiveness of certain variables to shocks and of transmission.

In previous work (Canova and De Nicoló (1995)) we have attempted to give a structural interpretation to the stock return-real activity relationship emerging from the reduced form evidence popularized by Fama (1990a), both within and across countries. Here we want to provide empirical evidence on a broader set of interactions among real and financial aggregates across countries and their international linkages, with the idea of shedding light on the structural nature of the relationships and of providing information needed for integrating financial markets into international models of the business cycle (see Ballabriga, Sebastian and Valles (1995) and Canzonieri, Valles and Vinals (1996) for other examples). We believe that this information is valuable not only for students of international business and financial cycles, but also for anybody engaged in international policy coordination activities.

The presentation of our empirical evidence is organized around three main questions. 
First, we would like to know whether innovations of nominal stock returns affect real activity and inflation, and, in turn, whether and how nominal stock returns react to innovations in real activity and inflation. The issue at stake is to what extent the dynamics of equity prices reflect news regarding changes in economic and policy fundamentals, and anticipate such changes. Such a question has received substantial attention in the literature, primarily in an attempt to explain the negative contemporaneous correlation between real stock returns and inflation emerging in the US. The explanation of the sign of this correlation proposed by Fama (1981) and Gerske and Roll (1983), based on the anticipatory movements of real stock returns for real activity and on a negative link between inflation and real activity, has been empirically examined for the US by various authors with mixed results (see e.g. James, Koreisha and Park (1985), Fama (1990b), Lee (1992)).

Second, we would like to assess whether, and to what extent, innovations in the slope of the term structure signal movements in real activity and/or inflation. The issue is whether the informational content of measures of the term structure is more related to (expected and unexpected) changes in the monetary policy stance or to future developments in the real side of the economy. This question is tightly linked to those posed by the literature which studies to what extent measures of the term structure of interest rates are leading indicators for inflation and real activity (see e.g. Stock and Watson (1989), Estrella and Hardouvelis (1991), Mishkin (1990), Harvey (1988) and Plosser and Rouwenhorst (1994)). Common to both branches of the literature, and to the suggested interpretation of the key relationships, is the implicit or explicit assessment of how monetary innovations and/or expectations about the future policy stance impact on financial markets.

Third, we would like to know whether inflation innovations propagate to real activity. Under the restrictive neoclassical interpretation that these innovations proxy for monetary surprises, this is the old and unsolved question concerning the "real effects" of monetary policy. Our contribution is to analyze the problem from an explicit cross-country and international perspective (see for complementary efforts Gerlach and Smets (1995) and Shijoi (1996a,b)) and to gauge the extent to which previous conclusions need to be modified once international interactions are explicitly taken into account.

Our findings suggest that the answers to the above questions are country dependent and that there are interesting and important international asymmetries. First, many of the empirical regularities typically found in the US are not present in European countries and appear in a different form in Japan. For example, the link between financial markets and real activity, as indicated by 
the forecasting power of the slope of term structure for real activity, and by the response of stock returns and the term structure to news in real activity, is significant for the US and almost absent for other countries. In addition, the US slope of the term structure has major predictive power not only for domestic inflation, but also for foreign inflation, while this is not the case for any other country's term structure. We argue that these asymmetries are consistent with an interpretation of the international dynamics where innovations to the growth rate of industrial production in the US appear to occur close to full capacity, influence stock returns and generate domestic inflationary expectations which are quickly incorporated in the slope of the term structure. Because foreign inflation increases following real US shocks, probably via imported inflation effects, the US term structure also predicts foreign movements in inflation. No such effect occurs in the other countries since real shocks do not typically generate inflationary expectations. Second, while international data demonstrates that integration in financial and real markets is well underway, it is surprise movements in US financial and real variables that lead and predict movements in financial and real foreign variables. Third, confirming previous analyses, we find that innovations in exchange rates have essentially no effect on either real or financial variables and that exchange rates barely respond to shocks in other variables. Finally, we fail to detect any significant dynamic one-way causality from inflation to the growth of real activity and any significant negative relationship between the two variables both in closed economy and international settings.

The structure of the paper is as follows. In section 2 we discuss the specification of the reduced form model and present the statistics we use to summarize the results. Basic measures of volatility, persistence and comovements of our dataset are discussed in section 3 . The dynamic interdependences emerging from closed and open economy VAR models are described and discussed in sections 4 and 5, respectively. Section 6 concludes.

\section{The specification of the VAR}

There are several problems connected with the specification of an empirical model which can be used to address the questions posed in the introduction. They concern the choice of a particular reduced form, the variables we want to include in the system, the question of how to appropriately describe the dynamics of the data and the issue of stationarity. We address these questions in turn.

The reduced form model we choose is an unrestricted VAR. There are three basic reasons for our choice: first, it is well known that a VAR is a good approximation to the DGP of any vector of time series as long as enough lags are included (see e.g. Canova (1995)); second, an unrestricted VAR 
is well suited to study interdependences because it captures the dynamic feedbacks present in the model in an unconstrained fashion and third, given VAR estimates of the parameters, interesting statistics used to gauge the strength and the direction of the transmission of shocks across domestic and international real and financial markets can be easily computed.

Ideally, to study the overall set of interdependences existing among the variables of interest one would like to include them all for all the countries we are interested in examining. Obviously this is not feasible: large systems are hard to handle and to interpret. With a sample of limited size, the parameters of large VAR systems will be poorly estimated and the extent of the dynamic interdependences obscured. Given these limitations, we proceed in two steps. First, we examine closed economy VAR models including a measure of nominal stock returns (SR), of the slope of the nominal term structure (TERM), of real activity (IP) and of inflation (INF). Second, we use a number of bilateral VAR models with the US as one country and Germany, Japan or the UK as the other country (as in Bekaert and Hodrick (1992)). Within each system we include, for each of the two countries, a measure of nominal stock returns, of the slope of the nominal term structure, of real activity, of inflation and the bilateral nominal exchange rate (E), for a total of 9 variables for each system. The exact description and the sources of the variables included in each system is provided in appendix A. The sample we use covers monthly data from 1973:1 to 1993:12. We choose to use monthly data to maximize the number of observations we have available and the information contained in the series. There is clearly a trade-off in using monthly data as the noise can be substantial and heteroschedasticity may be the problem with financial time series. In the last section of the paper we also discuss results obtained with quarterly data where both of these problems are of minor importance. The sample is chosen with two considerations in mind. First, because of structural breaks or existing restrictons in financial markets, the pre-1973 data are likely to be incompatible with the post-1973 data. Second, the sample 1973-93 appears to be more likely to display the international interdependences we are looking for.

Reduced form models, which include stock returns, real activity, inflation and a measure of real interest rates have been examined by many authors (e.g. Geske and Roll (1983); James, Koreisha and Partch (1985) or Lee (1992)). Here we maintain the same structure used by these authors except that we employ a measure of the slope of the term structure in place of a measure of short term interest rate. We do this because of recent results by Stock and Watson (1989), Estrella and Hardouvelis (1991), Bernanke and Blinder (1992), Plosser and Rowenshort (1994), demonstrating the superior predictive power of the term structure for real activity, relative to a single measure 
of short term interest rates, both in the US and in some European countries. In principle, a VAR could be better specified if both a short and a long term nominal rate are included. However, as argued by Bekaert and Hodrick (1992), this may create problems in handling non-stationarities. These problems are reduced, if not solved, by directly taking a measure of the slope of the term structure as basic variable of the system.

We choose to include nominal returns and an inflation rate instead of converting nominal returns into real ones using proxies for ex-post inflation or expected inflation prior to their use in the VAR (as in Lee (1992)), because results are more transparent in this way since the time path of real returns can be easily computed from estimated VAR coefficients. As Lee (1992) and others have stressed, the rate of inflation is very highly correlated with the growth rate of the monetary base (on average for the countries under consideration the contemporaneous correlation is about 0.7 ): by including them directly we can interpret inflation surprises as close proxies for monetary surprises. In addition, we include a measure of nominal exchange rates in the VAR to convert foreign nominal returns into domestic currency.

Although a VAR is a good approximation to any vector of time series when the sample size is unlimited, the degrees of freedom of the model will be quickly exhausted if we let the lag length grow to make the approximation as accurate as possible in finite samples. To optimally trade-off the quality of the approximation and the resulting overparametrization of the VAR several criteria have been designed. The most popular ones in the literature are the Akaike and the Schwarz criteria, which penalize overparametrized models adding little to the quality of the approximation. Here we use both criteria to determine how many lags should be included in each VAR model.

One issue of crucial importance in examining the structure of interdependences across markets and countries over the business cycle is the one of stationarity. To compute interesting statistics for the variables of the system and interpret responses to shocks as short term dynamics around a stationary (steady) state, the VAR system must be stationary, possibly around a deterministic trend. To insure that this is the case, it is typical to examine the order of integration of each of the variables of the system, control for the number of common stochastic trends in the VAR and, finally, appropriately transform the system to achieve stationarity. The effect of shocks on the level of the variables can then be recovered using the inverse of the transformations originally employed.

As expected, unit roots are found in the nominal exchange rate and the industrial production index while for the other three variables the unit root hypothesis is rejected for all countries. Cointegration tests suggests the lack of common trend between exchange rate and real activity. 
Therefore, we specify closed economy VARs with nominal stock returns, nominal slope of the term structure and inflation in levels and industrial production index in percentage changes. For open economy VAR models the nominal exchange rate in percentage changes is added to these variables. Given this structure, both the Akaike and the Schwarz criteria indicate that the short run dynamics of each of the models we examine is well described by a VAR(1), which we take as our basic structure in all of the exercises.

Because the VAR is a reduced form model, inference concerning the transmission properties of the model in response to structural disturbances can not be undertaken unless a behavioral system is identified from the reduced form evidence. In other words, we can not call a disturbance - say, to industrial production- a supply shock unless we have a behavioral model, nested in our reduced form VAR, describing how supply shocks influence the variables of the system. Because the task here is to describe the interdependences across markets and countries and suggest a tentative explanation for the structure of the linkages rather then testing the validity a particular model via the VAR, we proceed in a semi-automatic fashion and identify a structural model from the VAR using a Choleski decomposition of the covariance matrix of the shocks. To see exactly what this entitles consider the VAR model

$$
Y_{t}=A_{0}+A(\ell) Y_{t-1}+e_{t} \quad e_{t} \sim(0, \Sigma)
$$

where $Y_{t}$ is either a $4 \times 1$ or a $9 \times 1$ vector. Stationarity insures that (1) is invertible so that we can compute the moving average representation of the form:

$$
Y_{t}=(I-A(\ell))^{-1} A_{0}+(I-A(\ell))^{-1} e_{t}
$$

Because the covariance matrix of the VAR disturbances $\Sigma$ is non-diagonal it is impossible to decompose movements in each of the component of $Y_{t}$ into innovations due to any particular variable of the system. Our approach is to note that for any positive semi-definite nonsingular $\Sigma$ there always exists a decomposition $\Sigma=V V^{\prime}$ where $V$ is lower triangular orthogonal matrix so that (2) can be transformed to:

$$
\begin{aligned}
Y_{t} & =(I-A(\ell))^{-1} A_{0}+(I-A(\ell))^{-1} V u_{t} & \\
& =\mu_{0}+\sum_{s=0}^{\infty} C_{s} u_{t-s} & u_{t} \sim(0, I)
\end{aligned}
$$

where $u_{t}=V^{-1} e_{t}$ and $C(\ell)=(I-A(\ell))^{-1} V$. With this transformation the innovations are uncorrelated and it becomes possible to examine responses to innovation in each of the variables 
of the system. Note that while the contemporaneous (within one month) effects in the VAR are triangular, lagged dynamics are completely unrestricted. Therefore, the identification scheme is unlikely to induce distortions on the measures of the dynamic interdependences we are interested in examining.

There have been several criticisms in the literature to this semi-automatic approach (see e.g. Canova (1995) for a summary). Despite these criticisms it has become standard to examine this type of system as a benchmark to compare the implications of more complicated structural systems. If the innovations in the reduced form system are uncorrelated, all identification schemes which impose restrictions on the contemporaneous impact of shocks will produce identical results. In the less extreme event where innovations of the reduced form system are nearly uncorrelated, results will be qualitative robust to alternative identification schemes which impose restrictions on the covariance matrix of the shocks. In our case, the largest element of the covariance matrix of innovations does not exceed, in absolute value, 0.2 in all the systems we have examined. Therefore, the innovations we identified are a good approximation to more structurally identified innovations.

We focus on two statistics which summarize the interdependences of the various variables of the system: the impulse response and the variance decomposition. ¿From equation (3) the coefficients $C_{s}$ represent the matrix of demeaned responses $s$-periods ahead, $s=0,1, \ldots$, following unitary shocks in the variables of the system. Also the unconditional variance of $\hat{Y}_{t}$ is then $\sum_{j=0}^{\infty} C_{s} C_{s}^{\prime}$. ¿From (3) we can allocate the variance of each element in $Y_{t}$ to sources in elements of $u_{t}$, because the $u_{t}$ 's are both serially and contemporaneously uncorrelated. The statistic we consider is:

$$
z^{\tau}(i, j)=\frac{\sum_{s=0}^{\tau-1}\left(C_{s}^{i j}\right)^{2}}{\sum_{j=1}^{m} \sum_{s=0}^{\tau-1}\left(C_{s}^{i j}\right)^{2}}
$$

where $\sum_{j=1}^{m} z^{\tau}(i, j)=1 . z_{i, j}^{\tau}$ represents the component of error variance in the $\tau$-step forecast of $Y_{i}$ which is accounted for by innovations in $Y_{j}$. Because for $\tau \geq 12, z^{\tau}(i, j)$ is practically unchanged, we only report results for the two-years ahead variance decomposition (i.e., $\tau=24$ ).

Although it is standard to report point estimates of the impulse response and of the variance decomposition, a meaningful interpretation of the dynamic interdependences is impossible unless measures of dispersion are attached to the point estimate obtained. There are two ways to compute confidence interval for these statistics. One is the asymptotic criteria suggested by Lutkepohl (1991). The other is to construct confidence bands numerically using a Monte Carlo approach. Here we follow this second approach and obtain $95 \%$ intervals of the statistics drawing directly 
from the posterior distribution of the VAR coefficients. To do this, write the VAR in (1) as

$$
y_{t}=\left(I \otimes x_{t}\right) \beta+e_{t}
$$

where $\otimes$ is the Kroneker delta, $x_{t}$ is a vector of lagged $y_{i t}, i=1, \ldots, m$ and $\beta$ is a vector containing the stacked version of the $A(\ell)$ and of the $A_{0}$ matrices. Denote the OLS estimates of $\beta$ and $\Sigma$ by $b$

and $S$. If we assume that the prior on $\beta$ and $\Sigma$ is $f(\beta, \Sigma) \propto|\Sigma|^{\frac{(m+1)}{2}}$, the posterior distribution for $\beta$, conditional on $\Sigma$, is normal with mean $b$ and covariance matrix $\Sigma \otimes\left(x^{\prime} x\right)^{-1}$ and the distribution of $\Sigma^{-1}$ is Wishart $\left((\mathrm{TS})^{-1}, \mathrm{~T}\right)$, where $T$ is the sample size. Confidence intervals for $C_{s}$ and $z^{\tau}(i, j)$ can be computed by drawing $Q$ times from the above distributions for $\beta$ and $\Sigma$, inverting the VAR and finding the matrix $V$, computing $\left[C_{s}\right]^{q}$ and $\left[z^{\tau}(i, j)\right]^{q}, q=1,2, \ldots, Q$ and appropriately ordering the replications. As suggested by Sims and Zha (1995), directly computing small sample confidence intervals out of replications, instead of using an asymptotic normal approximation, reduces the skewness and the asymmetries in the impulse response bands due to small sample sizes.

\section{A Summary of the Properties of the Data}

An overview of the properties of our data appears in Table 1 which presents the mean, the standard error, the first four autocorrelations for each variable and selected cross correlations. Figure 1 plots the relevant time series. Overall, it appears that there are some cross country variations, but their magnitude is small. On average, over the period 1973-1993, stock returns were of the order of $1 \%$ per month; the term structure was slightly upward sloping; the dollar depreciated against the Yen and the Deutch Mark and appreciated with respect to the Pound; the growth rate of industrial production was approximately $0.2 \%$ per month and the inflation rate was approximately $0.5 \%$ per month in all countries. Stock returns are significantly more volatile than any other series, followed by exchange rate changes. The least volatile series is the slope of the term structure for all countries.

Autocorrelations are typically small, and if not, decay quickly to zero. The exceptions are the slopes of the term structure which, in agreement with the findings of Plosser and Rouwenshort (1994), are highly serially correlated and very persistent in all countries. Because the standard deviation of these series is small, it must be the case that either the slope of the term structures is approximately constant, or that its random component has a very small error relative to the level of the series for each of the four countries.

Domestic cross correlations overwhelmingly suggest the presence of fairly weak relationships among the variables except, perhaps, in the US. Nominal stock returns and inflation are negatively 
contemporaneously related in the US, Japan and Germany (contrary to a simple version of the Fisher hypothesis) and positively correlated in the UK, but the correlation is statistically insignificant except for the US. Also, no relationship between nominal stock returns and current or future industrial production growth emerges. This is not necessarily in contrast with the evidence of Fama (1981) or Lee (1992) as we consider nominal (as opposed to real) stock returns. Conversely, there is a comparatively stronger link between the slope of the nominal term structure and inflation in all countries (in agreement with Fama (1990b) and with some of the findings of Mishkin (1990)). Correlations are significantly negative for the US, Germany and Japan, and significantly positive for the UK, with the US exhibiting the largest correlation.

There is some correlation between the slope of the term structure and industrial production growth, but its magnitude is small and significant only in the US (in agreement with the findings of Stock and Watson (1989) and Estrella and Hardouvelis (1991)) and Japan. This seems at variance with the findings of Plosser and Rowenshort (1994) for some European countries, even though differences may be due to the sample periods and the frequency of the data. Exchange rate changes are somewhat more correlated with domestic inflation rates than with industrial production growth, but differences are small and all correlations are insignificantly different from zero. Finally, inflation rates are negatively associated with subsequent growth in industrial production in all countries, but, once again, the relationship is statistically very weak.

International correlations indicate that comovements in stock returns and inflations are much more syncronic then cross country comovements in the slopes of the term structures and industrial production. Surprisingly low are the cross country correlations of industrial production growth, which contrast with the relatively large cross country correlations of quarterly GNPs (see, e.g., Backus, Kehoe and Kydland (1992), p.752). Also to be noticed is the strong persistence of cross country correlations of the slope of the term structures and of inflations.

\section{Closed Economy Dynamic Interdependences}

Our discussion of closed economy interdependences is based on Table 2 and on Figures 2-5. Table 2 reports median values of the variance decomposition for each of the four single country VARs, and $\mathrm{a}^{*}$, indicates that the 5th percentile of the empirical distribution of the decomposition is above $5 \%$ (so that median values are significantly different from zero). Figures $2-5$ present median responses and $90 \%$ confidence bands. 


\subsection{Shocks to Stock Returns}

Shocks to domestic stock returns induce a small positive median response in the slope of the term structure in the US and Germany, a negative median response in Japan and a mixed one in the UK. Also, they generate negligible median responses of industrial production growth in all countries, except perhaps, at impact. The sign of the median response of inflation depends on the country: inflation slightly decreases in the US, increases in the UK, and exhibits negligible movements in Germany and Japan. In all cases responses are insignificant as the $95 \%$ confidence bands include zero.

Overall, nominal stock returns appear to be exogenous in all four countries VAR (at least $93 \%$ of the variance of each country stock returns is explained on average by its own innovations) and their innovations explain a small proportion of the variance of the other variables in each country. These conclusions contrast with several results reported in the literature. They are at variance with those of Gerske and Roll (1983), who claim that nominal stock returns have some predictive power for inflation, with those of James, et al. (1985), who suggest that nominal stock returns have predictive power for both real activity and inflation, and those of Lee (1992), who claims that real stock returns lead real activity. These differences may be due to the sample period we use, which is shorter and does not overlap with the one used by the above authors.

\subsection{Shocks to the Slope of the Term Structure}

Innovations to the slope of the domestic term structure induce persistently positive median responses in the slope of the term structure, positive median response in stock returns and in industrial production growth in all countries. They also induce a negative median response of inflation in all countries but the UK, where the median response is positive after a small decline at impact. Note, however, that stock returns responses are insignificantly different from zero in all countries; that only industrial production growth responses in US and Japan are significant after few periods, while inflation responses are significant in all countries but the UK.

Innovations to the slope of the term structure explain both a large proportion of their own variability and differential amounts of the variance of inflation and industrial production growth in each of the four countries: the largest is for the US, with median values of $32.6 \%$ and $7.6 \%$, and the smallest for the UK, with median values of $4.5 \%$ and $0.9 \%$, respectively. The slope of the term structure appears to be causally prior to inflation, particularly in the US and Japan, and

to industrial production in Japan. In the US, the causality ordering between term structure and 
industrial production growth is unclear: $14.6 \%$ of the variance of the slope term structure at the 2-years horizon is explained by innovations in industrial production growth, while only $7.6 \%$ of the variance of industrial production growth is explained by innovations in the term structure slope. In Germany and the UK the slope of the term structure is unrelated (in a forecasting sense) to both industrial production growth and inflation.

In sum, and in agreement with the predictions of Fama (1990b) and to some extent Mishkin (1990), the slope of the term structure typically has a much larger explanatory power for inflation than for industrial production growth. However, there are significant differences across countries in the fraction of the variability of inflation and real activity explained by surprise movements in the slope of the term structure.

\subsection{Shocks to Real Activity}

Innovations to IP growth produce heterogeneous median responses in the variables for all four countries under consideration. The median response of stock returns are negative in the US and Japan (so nominal stock returns are countercyclical) and positive in Germany and the UK; the median response of the slope of the term structure in negative the US and the UK (so the slope is countercyclical) but positive in Germany and Japan. Finally, the median responses of inflation are positive in US and Japan (so inflation is procyclical) but negative in UK and Germany. The magnitude of the responses of the slope of the term structure and of inflation is small in all countries; for the US, all median responses are significantly different from zero (the one of stock returns only for a short period) while the ones for the other countries are not.

Shocks to the growth rate of industrial production explain on average a very small fraction of the variability of the other variables in all countries except in the US, where they account for $14.6 \%$ of the variability of the slope of term structure and $11.1 \%$ of the variability of inflation. The evidence for the US economy seems consistent with the idea that an innovation in US industrial production growth - which is generally more persistent than in other countries - typically occurs close to full capacity, it induces an increase in short term rates relative to long term ones, an increase in inflation and a decline in nominal stock returns. None of these effects is present in the other three countries. 


\subsubsection{Shocks to Inflation}

Innovations to inflation are somewhat persistent in all countries; they induce negative median responses of stock returns in all countries except the UK; negative median response in the slope of the term structure in US and positive median responses in UK and Germany; and negligible ones in Japan. The median responses of industrial production growth are in general negative, typically after a lag, except for Japan. The $90 \%$ confidence band for the responses of all variables include zero for all lags with the exception of the US stock return responses, which are significantly negative for a quarter after the shocks.

Hence, innovations in inflation have little predictive power for the variability of any variabile for all four countries. The variance of inflation is explained primarily by its own innovations in Germany and UK, while in the US and Japan, innovations in the slope of the term structure and in inflation explain a significant portion of inflation variability.

\subsection{Summary}

Although the evidence for the US we have presented is fairly consistent with previous analyses conducted with US data, the results demonstrate substantial heterogeneities across countries.

- In the US, the term structure predicts real activity and inflation better than nominal stock returns, which appear to be unrelated to the other three variables. The forecasting power of the slope of the term structure is stronger for inflation; the proportion of the variance of industrial production growth explained by innovations in the term structure is small although significant. The relationship between nominal (and real) stock returns and inflation is significantly negative, albeit small, and is almost entirely due to the negative response of nominal stock returns to inflation innovations.

- In the UK and Germany the interdependences between stock returns, slope of the term structure, growth rate in real activity and inflation are very small. The stochastic process for each of these four variables is very well represented by a univariate $\operatorname{AR}(1)$ process. Consequently, movements in financial markets have very little forecasting power for both real activity and inflation; there is no significant relationship between nominal stock returns and inflation while real stock returns and inflation are strongly negatively correlated. For these two countries there is a small positive dynamic correlation between stock returns and industrial production growth and a small negative dynamic correlation between industrial production growth and 
inflation (in line with Fama's (1981) suggestions).

- Japan appears to be an intermediate case between the previous two. There is a significant relationship among the slope of the term structure, the growth rate in industrial production and inflation, but the forecasting content of the term structure for these variables is small. The relationship between nominal stock returns and inflation is negative but insignificant. The sign of this relationship is due to both negative responses of inflation to stock return surprises and to negative stock return responses to inflation surprises. The relationship between real stock returns and inflation is negative and significant.

\subsection{Discussion}

We now turn to discuss what our results tell us about the questions of interest in this paper.

Consider first the relationship between asset returns and inflation. We have seen from Table 1 neither the sign nor the magnitude of the dynamic correlations is robust across countries. Figures 2 to 5 indicate that nominal stock returns are significantly negatively correlated to inflation only in the US, since the other countries exhibit insignificant responses of stocke returns to inflation, while in the other countries the dynamic correlation is insignificant. This lack of robustness can be interpreted in several ways. First, it is possible that stock markets in Japan and Germany are comparatevely thinner or less affected by international capital flows and do not respond in a consistent way to news coming from the monetary side of the economy. Alternatively, it could be the case that inflation negatively affects nominal stock returns but that this effect is masked by contemporaneous movements in government controlled short-term interest rates. The mechanism through which the negative correlation emerges for the US is slightly different from the one proposed in the literature: nominal and real stock returns are directly and negatively linked to inflation, without any intermediate effect on industrial production growth.

Second, in all four countries the slope of the term structure has a better predictive power for inflation than for the growth rate of real activity. Therefore, surprise movements in the slope of the term structure capture more expectations about the future state of the monetary policy stance than future developments in the real side of the economy. Within this general tendency there are substantial diversities across countries. In the US and Japan, in addition to predicting inflation, the slope of the term structure has a significant, albeit small, predictive content for real activity while in the UK and Germany this is not the case. Lastly, contrary to Mishkin (1990), we find that the predictive power of the slope of the term structure for real activity and inflation in each of the 
four countries does not substantially vary with the forecasting horizon.

Finally, the relationship between inflation surprises and real activity display important heterogeneities. In this case as well the US stands on its own with one way causality running from real activity to inflation being strong and significant. For the other three countries, the dynamic relationship between inflation and industrial production growth is weak and no significant causality emerges, even though inflation surprises produce negative median responses of industrial production growth in the UK and Germany.

\section{International Dynamic Interdependences}

We next turn to study interdependences among the four industrialized countries we previously considered in isolation. Median values for the variance decomposition results are in Table 3 where, again, a ${ }^{*}{ }^{\prime}$ indicates that the 5 th percentile of the empirical distribution of that decomposition is above $5 \%$.

\subsection{Shocks to Stock Returns}

Innovations in US nominal stock returns are instantaneously transmitted across the world and induce a statistically significant and positive median response in nominal foreign stock returns. These shocks also generate median responses in the slope of the term structure which are positive in US, Japan and Germany, and negative in the UK, a small appreciation of the dollar; a small positive median response of industrial production growth both in the US and abroad; and a negative median response of US, German and Japanese inflation, whereas UK inflation temporarily increases. None of these responses is, however, statistically different from zero.

Median responses of US variables to shocks in foreign stock returns are, in general, small and insignificantly different from zero regardless of the country where they are generated, while median responses of foreign variables are similar to those found in the closed economy setup.

A significant portion of the variability of foreign stock returns is explained by US stock returns innovations (from 9.7 to $22.2 \%$ ) but not viceversa. The explanatory power of domestic and foreign stock returns innovations for industrial production growth or inflation in all countries is always very small. Finally, surprise movements in Japanese stock returns explain a small but significant portion of the variability of the yen-dollar rate of change at the 24 month horizon.

Overall, the results suggest that stock markets are sufficiently well integrated internationally with causality running from the US to foreign stock markets and with the transmission mechanism 
being almost identical in the three countries. However, stock returns have little connections with bond markets, real activity or inflation: the responses of all variables are economically interpretable (a surprise increase in nominal stock returns drives up industrial production growth and inflation and drives down short term interest rates) but small and statistically insignificant.

\subsection{Shocks to the Slope of the Term Structure}

A shock to the slope of the US term structure generates positive median responses of stock returns in the US and abroad, persistent median responses in the slope of the term structures, a small dollar appreciation; an increase in IP growth in the US but not abroad; and a drop of inflation in all countries. However, the only responses which are significant are those of inflations and of US industrial production growth.

Surprise movements in the slope of the US nominal term structure account for a significant proportion (about 19\%) of the Japanese slope of term structure and for smaller and insignificant portions of variability of Germany and UK term structure at the 24 month horizon. As in the close economy setup, variations in the slope of the term structure in the US account for a mere $6-8 \%$ of the variability of domestic industrial production growth and for almost nothing of the variability of foreign industrial production growth, while the proportion of US industrial production growth explained by surprise movements in foreign term structure is even smaller. The slope of the term structure in the U S still explains about $30 \%$ of the variability in inflation forecasts in the US, and between 12 and $16 \%$ of the variability of foreign inflation.

The effects of shocks to the foreign slope of the term structure on US variables depends on the country where they originate. If the shock comes from Japan or the UK, there is a slight negative median response of US stock returns, a positive median response of the US slope of the term structure and of IP growth and a negative median response of US inflation. If the shock originates in Germany the mean responses of US variables are all positive albeit small.

In sum, as in closed economy setups, the informational content of the slope of term structure for inflation and IP growth differ across countries. However, once movements in the slope of the US term structure are taken into account, the slope of the foreign term structures contains very little information for foreign inflation and IP growth. In addition, the slope of the Japanese term structure tends to comove and be explained by surprise movements in the slope of the US term structure, with this one-way link being statistically significant. US and European bond markets, on the other hand, appear to be linked only indirectly through comovements of inflation rates. 


\subsection{Shocks to Foreign Exchange Markets}

The pattern of responses to shocks to foreign exchange markets is less straightforward and substantially more heterogeneous then the previous ones. The only pattern which deserves some comment is the boost in industrial production growth which occur when the dollar appreciates. This real effect is present, to a smaller extent, in all countries. However, after a few months inflation increases in the US and Germany and decreases in the UK and Japan. Hence, it appears that a temporary dollar appreciation signals positive real prospects for the US economy but creates inflationary pressures which drive short term interest rates up in US and UK and down in Germany and Japan relative to long term ones.

The percentage of the variance for all variables explained by surprise movements in changes in the exchange rates is quite small. In general, and in agreement with the existing literature (see, e.g., Meese and Rogoff (1983)), exchange rate movements appear to be exogeneous with respect to all the variables in every system.

\subsection{Shocks to Real Activity}

Innovations to industrial production growth in the US have strong and significant repercussions in the world economy: they tend to be transmitted to foreign industrial production growth, increase domestic inflation, induce a decline in slope of the domestic term structure and generate a small lagged drop in nominal stock returns in all countries. Shocks to foreign industrial production growth, on the other hand, generate little dynamics in the system except for small movements in US and foreign stock returns of the same sign.

Innovations in US IP growth explain a significant portion of the variability of US term structure and of inflation (about 9-10\%) and a smaller but still significant portion of the variability of Japan and UK IP growth. No real transmission occurs between the US and Germany and innovations in German IP growth have explanatory power only for their own variability.

In conclusion, in agreement with the closed economy evidence, shocks to IP growth induce statistically significant domestic responses only in the US. In addition, IP growth shocks tend to be transmitted to the real sectors across countries mainly if they occur in the US. Moreover, the international spillover of real shocks to financial markets differs according to the pair of countries considered. Foreign stock returns decline following a positive innovation in US IP growth and US stock returns increase following a foreign IP growth shock. The responses of the slopes of the term structure, on the other hand, show very little cross country regularities. 


\subsection{Shocks to Inflation}

Innovations to the US inflation rate generate a series of adjustments which are common to all countries. They induce a lagged drop in domestic and foreign stock returns, small movements in the opposite directionm in the term structures of US and the foreign country, a small lagged decline in foreign IP growth, and a sizable but insignificant increase (both contemporaneous and lagged) in the foreign inflation rate.

The dynamic effects of shocks to foreign inflation depend on the country where they originate. In general, they induce insignificant responses in stock returns across countries, an increase in US inflation, no effects on US IP growth but a significant drop in German and UK IP growth. All of these responses are small and shocks to inflation rates explain a small and statistically insignificant proportion of the variability of all series except inflation.

Hence, inflation surprises have negligible influences on the growth rate of real activity and nominal (but not real) stock returns in all countries, and even US inflation innovations have small international repercussions. There is a positive relationship between inflation surprises and median responses in the slope of the term structure in the US while in the other countries the relationship is negative (long term rates react more strongly than short term ones). Finally, in agreement with closed economy results, the growth rate of US industrial production is causally prior to US inflation.

\subsection{Summary}

Our investigation of the international interdependences has highlighted the following facts:

- Stock markets are well integrated across the world with strong unidirectional causality running from US nominal returns to nominal returns of the other countries. Bond markets appear to be less integrated than stock markets, but there is a significant one-way causality from the US bond market to the Japanese one.

- Innovations to the growth rate of US IP growth are transmitted with a small lag to IP growth of other countries: the magnitude of the responses however depends on the pair of countries considered, German IP growth is practically unaffected by developments in the real side of the US economy.

- Inflation surprises are transmitted in a more symmetric way across countries, but foreign responses are typically insignificantly different from zero. 
- Shocks originating in foreign exchange markets have no impact on any of the variables of the system and exchange rate changes are almost enterely explained (in a dynamic sense) by their own innovations.

- In agreement with closed economy results, the dynamic correlation between nominal stock returns and inflation is significant only in the US. Also, stock returns have no predictive content for developments in the real side of the economies under consideration.

- In agreement with Plosser and Rouwenshort (1994), we find that innovations in the slope of the US term structure carry information about future US inflation even in open economy frameworks, but the information is not entirely nominal since movements in the slope also signal future movements in US IP growth. Because, as noted in section 3 , inflation rates comove across countries, innovations in the slope of the US term structure also carry information about future movements in foreign inflation rate. This predictive power is however a prerogative of the US term structure: not only do none of the three foreign slopes have any predictive power for US inflation, but they also have no predictive power for their domestic inflation, once the predictive effect of the slope of the US term structure is factored in. This is particularly relevant for Japan since the slope of the term structure had some predictive power for domestic inflation and IP growth in a closed economy setup.

\subsection{Discussion}

We now turn to discuss what our international results have to say for our three questions of interest.

The presence of international linkages does not change the basic features of the relationship between stock returns and inflation. Nominal stock returns surprises do induce positive median responses of industrial production growth and, with some qualifications, negative median responses of inflation, but the link is very weak in all countries. On the other hand, inflation surprises induce negative median responses in nominal and real stock returns but insignificant movements in industrial production growth. What is important to note here is that the negative link between industrial production growth and inflation, which is at the basis of the explanation of the phenomenon proposed by Fama (1981), seems to be missing when international influences are allowed.

As we have seen, the predictive power of the term structure is altered in international contexts. It is only the slope of the US term structure which retains predictive power for inflation and IP growth across countries. Moreover, the US slope of the term structure predicts primarily inflation rates and, to some extent, term structure movements across countries. 
A possible economic expanation for these observations is the following: innovations in the growth rate of industrial production in the US have little real domestic expansionary effects (probably because they occur close to full capacity) and are typically expected to generate inflationary pressures which are, in general, trasmitted across countries. The domestic slope of the term structure anticipates these effects, with short term interest rates reacting more than long term ones, therefore acquiring predictive content for inflation but not for industrial production growth because of the small persistence of these innovations. Note that none of these effects appear in countries other than the US: innovations in IP growth appear to occur at less than full capacity, induce dynamics primarily in IP growth, and are typically not expected to generate inflation.

Next, we turn to the final question of interest, i.e., the effects of inflation innovations on real activity. Consistently with the closed economy characterization, surprise movements in inflation generate median responses in IP growth which are negative but insignificant. Note also that, although no direct causality from US inflation to foreign inflation exists, inflationary pressures in the US indirectly influence the variability in foreign inflation rates via term structure effects. These inflationary pressures do not affect directly foreign IP growth, probably because of neutralizing responses of local monetary authorities. Overall, international inflation rates appear to be passively reacting to the developments of the real side of the US economy, and do not have any predictive content for cyclical movements in the real side of the domestic economies for the sample under consideration.

It should be pointed out that these results do not imply that monetary policy has no effects on the real side of the economy. They simply say that, over the last 20 years, neutralization of unexpected imported inflation was one of the major goals of monetary policy in Japan, the UK and Germany, and that the real effects due to unexpected movements in the monetary policy stance have been negligible. Hence, monetary policy appears to have been sufficiently "credible" and very little attempts have been made to deviate from the proposed monetary goals.

We have examined the robustness of our results along two dimensions. First, we have considered quarterly VAR (both domestic and international). Fama (1990a) argued that, at least in the US, real stock market returns predict industrial production growth better when low frequency data are used. Here, we are interested in knowing whether the use of lower frequency data brings about changes in the strength and/or direction of the impulse and propagation mechanisms we have documented. Second, we have considered bilateral VARs with stock returns expressed in one currency (the US\$) to assess whether returns uncovered for exchange rate risk might have 
different informational content for the dynamics of the other variables. While we found no relevant changes in this latter case, we noticed some interesting differences when quarterly data are used. In particular, three results stand out. First, changes emerge for the US but not for the other three countries. Second, financial variables (in particular, nominal stock returns) do have a larger predictive power for the variance of industrial production growth (they now account for $15 \%$ of the variance). Conversely, industrial production growth innovation now explain a significant portion $(9 \%)$ of variance of nominal stock returns. Finally, the level of dynamic interdependences in the US increases substantially both when we consider domestic and international systems.

Although the results we have presented are somewhat strong, a word of warning should be given. The conclusions drawn are based on the evidence obtained from a relatively short and, in some sense, peculiar sample. Therefore, results need not be robust to extensions of the sample size to, e.g., the relatively quiet non-inflationary period of the 1960s. Moreover, major modifiations in the real and financial sides of the four economies we consider have occurred over the 1973-1993 sample. For example, the UK and Japan enjoyed financial deregulation at the beginning of the 1980s; the Fed change operating targetting at the end of the 1970s and again at the beginning of the 1980s and the same type of change occurred in the UK after Margaret Thatcher took power. All these events suggest the potential presence of structural instabilities which may make the analysis sample dependent. We have tried, either by breaking or by appropriately shortening the sample, to assess the importance of these instabilities. We have found that the main qualitative conclusions remain, but also that, quantitatively, the effects we describe are less signinficant when the sample size is smaller.

\section{Conclusions}

This paper has analyzed the interdependences among financial markets, real activity and inflation from a multicountry and international point of view. The goal was to provide a series of stylized facts that could be used, on one hand, to evaluate the robustness of some key relationships documented by financial economists for the US, and on the other, to assess the quality of the outcomes of international business cycle models with money and financial assets.

Our results suggest that heterogeneities in the impulse and propagation mechanism of shocks across countries dominate over similarities. In particular, many of the regularities typically described for the US are missing from the other three economies we have analyzed. These facts highlight that a more robust test of business cycle models should be based on their capacity of 
replicating some of the key heterogeneities present in international data.

We believe that some of our findings might be useful in designing effective international policy coordination activities in the context of a tightly integrated world economy, issues which are high on in the policymaking agenda. First, notwithstanding the relative decline of the weight of the US in the world economy over the last 20 years, it is still true that shocks originating in the US have important real and informational effects that shocks generated in the other economies do not possess. If designing common policies in the face of cyclical fluctuations is considered one of the goals of international policy coordination, this fact suggests that the US is still a key counterpart that any country, including the European Union, should confront. Second, the primary source of disturbances at national and international levels appear to be shocks originating in real activity, whereas those originating in financial markets or attributable to a restrictive view of monetary policy have an insignificant role in generating significant cyclical fluctuations. These findings should be kept in mind both in discussing convergence indicators and in formulating feasible international policy objectives. Third, the responses of domestic inflation to shocks in both domestic and international real activity we have found are consistent with the idea that monetary policy in Germany (and to some extent the UK) has been effective in neutralizing both domestic and imported inflation. In addition, the lack of any significant causality from inflation to the growth of real activity within and across countries indicates that over the last 20 years monetary policy may have been an effective tool, devoid of real effects, in controlling inflation. Finally, at variance with arguments regarding the destabilizing effects of exchange rate uncertainty, often voiced in the policy circles and in the popular press, is the finding that exchange rate innovations have essentially no effect on any of the variables of the systems we have analyzed. Confirming previous analyses, we also find that exchange rate changes are in general insensitive to innovations in economic fundamentals. 


\section{Appendix}

\section{A. Definition of Variables}

The basic series employed in this study are: share price indexes for national stock markets (SH), dividend yields on stock market indexes (DY), nominal yields on short and long term government bonds (IRS) and (IRL), consumer price indexes (CPI), industrial production indexes (IP) and nominal exchange rates vis-a-vis the US \$ (EX). Sources: OECD or IFS (IMF) unless indicated otherwise.

The derived series are: nominal stock returns, obtained using the ratio of stock price index (SR) and dividend yields at time $(\mathrm{t})$ :

$$
R E T_{t}=\frac{S H_{t+1}-S H_{t}}{S H_{t}}+D Y_{t}
$$

slope of nominal term structure, obtained as the difference between yields on long term and short term government bonds:

$$
T E R M_{t}=I R L_{t}-I R S_{t}
$$

Sample: 1973.1-1993.12

\section{B. Data Sources}

\section{United States}

SH Monthly Standard \& Poor 500 industrial share price index (1985=100), daily averages.(OECD)

IRS Monthly interest rate on 3 month treasury bills (avg. of daily auction rates during the week of the last monday of the month). (OECD).

IRL Monthly interest rate on long-term Government bonds, 10 years or over (daily averages). (OECD).

DY Monthly Standard \& Poor 500 dividend yield (MF1431). (Datastream International).

CPI Consumer prices all items (not seasonally adjusted), 1985=100. (OECD).

IP Industrial production (seasonally adjusted). 1985=100 (OECD).

\section{Japan}

SH Monthly Tokyo stock exchange share price index, end of period data (1985=100). (OECD).

IRS Monthly 3 month Gensaki rate. (OECD).

IRL Monthly interest rate on long-term Central Government bonds, 5 years or more (end of the period). (OECD).

DY Monthly Tokyo Stock Exchange dividend yield (Topix). (Datastream International).

CPI Consumer prices all items (not seasonally adjusted), 1985=100. (OECD).

IP Industrial production (seasonally adjusted, but not adjusted for unequal number of working days in the month). $1985=100$. (OECD).

EX Market exchange rate vis a vis the US dollar. (IMF, IFS database 1994).

\section{United Kingdom}


SH Monthly F.T. Actuaries (500 shares) share price index, end of period data $(1985=100)$. (OECD).

IRS Monthly interest rate on 3 month treasury bills (avg. rate of allotment on last issue of month). (OECD).

IRL Monthly interest rate on long-term Government bonds, 5 years or more (last Friday of the month). (OECD).

DY Monthly F.T. Actuaries dividend yield (FTUKALY). (Datastream International).

CPI Consumer prices all items (not seasonally adjusted), 1985=100. (OECD).

IP Industrial production (seasonally adjusted). 1985=100 (OECD).

EX Market exchange rate vis a vis the US dollar. (IMF, IFS database 1994).

Germany

SH Monthly Federal Statistical Office industrial share price index, daily averages $(1985=100)$. (OECD).

IRS Monthly interest rate on 3 month loans (avg. of daily rate) (OECD)

IRL Monthly interest rate on long-term Government bonds, 5 years or more (end of the period). (OECD).

DY Monthly dividend yield. (Datastream International Total Market Return index).

CPI Consumer prices all items (not seasonally adjusted), 1985=100. (OECD).

IP Industrial production (seasonally adjusted). 1985=100 (OECD).

EX Market exchange rate vis a vis the US dollar. (IMF, IFS database 1994). 


\section{References}

[1] Backus, D., Kehoe, P. and F. Kydland, 1992, "International Business Cycles", Journal of Political Economy, 100, 745-775.

[2] Bekaert, G. and R. Hodrick, 1992, "Characterizing Predictable Components in Excess Returns on Equity and Foreign Exchange Markets", Journal of Finance, XLVII, 467-509.

[3] Ballabriga, F., Sebastian, M. and J. Valles, 1995, "European Asymmetries", forthcoming, Journal of International Economics.

[4] Bernanke, B. and A. Blinder, 1992, "The Federal Funds Rate and the Channels of Monetary Transmission", American Economic Review, 82, 901-921.

[5] Boldrin, M., Christiano, L. and J.D.M. Fisher, 1995, “Asset Pricing Lessons for Modelling Business Cycles", NBER working paper 5262.

[6] Cochrane, J. and L.P. Hansen, 1992, "Asset Pricing Explorations for Macroeconomics", NBER Macroeconomics Annual, 1992, 7, 115-165.

[7] Canova, F., 1995, "VAR: Specification, Estimation, Testing and Forecasting", in Pesaran, H. and M. Wickens, eds., Handbook of Applied Econometrics, 31-65.

[8] Canova, F. and G. De Nicoló, 1995, "Stock Returns and Real Activity: A Structural Approach", European Eeconomic Review, 39, 981-1015.

[9] Canzonieri, M., Valles, J. and J. Vinals, 1996, "Do Exchange Rates Move to Address Regional Imbalances?", Bank of Spain, manuscript, 1995.

[10] Danthine, J.P. and J.B. Donaldson, 1994, "Asset Pricing Implications of Real Market Frictions", Universite' de Lausanne, Working Paper \# 9504.

[11] Estrella, A. and G. Hardouvelis, 1991, "The Term Structure as Predictor of Real Economic Activity", Journal of Finance, XLVI, 555-576.

[12] Fama, E., 1981, "Stock Returns, Real Activity, Inflation and Money", American Economic Review, 25, 59-76.

[13] Fama, E., 1990a, "Stock Returns, Expected Returns and Real Activity", Journal of Finance, XLV, 1089-1108.

[14] Fama, E., 1990b, "Term Structure Forecasts of Interest Rates, Inflation and Real Returns", Journal of Monetary Economics, 25, 59-76.

[15] Gerske, R. and R. Roll, 1983, "The Monetary Linkage Between Stock Returns and Inflation", The Journal of Finance, XXXVIII, 1-33.

[16] Gerlach, S. and F. Smets, 1995, "The Monetary Transmission Mechanism: Evidence from the G-7 Countries", mimeo, Bank for International Settlements.

[17] Gordon, S. and E. Leeper, 1994, "The Dynamic Impacts of Monetary Policy: An Exercise in Tentative Identification", Journal of Political Economy, 102, 1228-47.

[18] Harvey, C., 1988, “The Real Term Structure and Consumption Growth”, Journal of Financial Economics, 22, 305-333.

[19] James, C., S. Koreisha and M. Partch, 1985, "A VARMA analysis of the Causal Relation among Stock Returns, Real Output and Nominal Interest Rates, The Journal of Finance, XL, $1375-1384$.

[20] Lee, B.S., 1992, "Causal Relations Among Stock Returns, Interest Rates, Real Activity, and Inflation, The Journal of Finance, XLVII, 1591-1603. 
[21] Lutkepoh1, H., 1991, "Introduction to Multiple Time Series Analysis", Springer and Verlag.

[22] Meese, R. and K. Rogoff, 1983, "Empirical Exchange Rate Models if the 70s: Do they fit out of sample?", Journal of International Economics, 14, 3-24.

[23] Mishkin, R, 1990, "What does the term structure tell us about future inflation?", Journal of Monetary Economics, 25, 77-95.

[24] Plosser, C. and G. Rouwenhorst, 1994, "International Term Structure and Real Economic Growth", Journal of Monetary Economics, 33, 133-155.

[25] Shijoi, E. (1996a), "External Shocks and Spanish Monetary Policy", mimeo, Universitat Pompeu Fabra.

[26] Shijoi, E. (1996b), "Identifying Monetary Policy in Japan”, mimeo, Universitat Pompeu Fabra.

[27] Sims, C., 1992, "Interpreting the Macroeconomic Series Facts: the Effects of Monetary Policy", European Economic Review, 36, 975-1011.

[28] Sims, C. and C. Zha, 1995, "Error Bands for Impulse Responses", Federal Reserve Bank of Atlanta, working paper 95-6.

[29] Stock, J. and M. Watson, 1989, "New Indexed of Coincident and Leading Economic Indicators", NBER Macroeconomic Annual 1989, 4, 351-393. 
Table 1: Summary Statistics

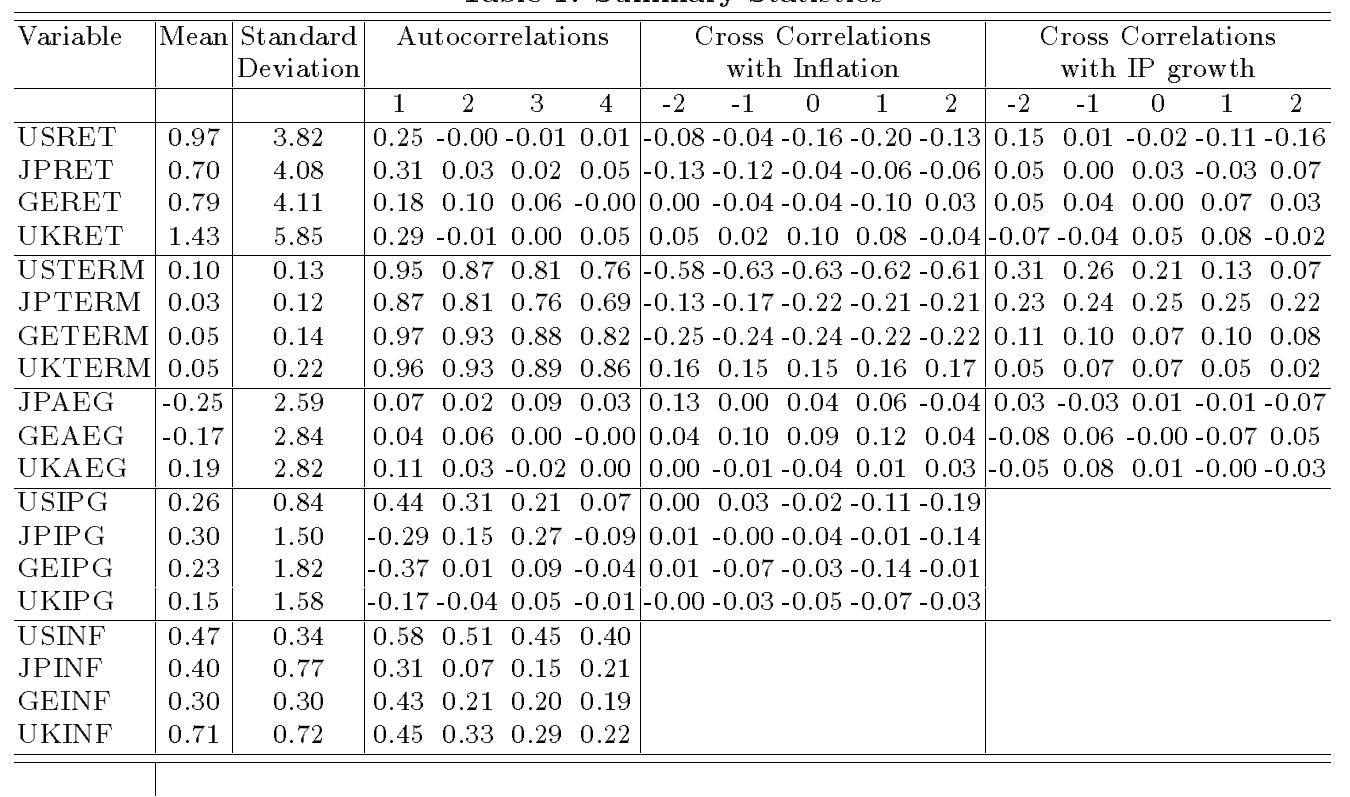

\begin{tabular}{lccccc}
\hline \hline \multicolumn{5}{c}{ Cross Correlation } \\
& -2 & -1 & 0 & 1 & 2 \\
\hline JPRET & with USRET & \\
JPE & 0.04 & 0.10 & 0.37 & 0.29 & 0.09 \\
GERET & 0.03 & 0.04 & 0.41 & 0.23 & 0.03 \\
UKRET & 0.02 & 0.18 & 0.52 & 0.31 & -0.01 \\
\hline \multicolumn{5}{c}{ with USTERM } \\
JPTERM & 0.13 & 0.14 & 0.18 & 0.22 & 0.23 \\
GETERM & 0.26 & 0.26 & 0.27 & 0.29 & 0.30 \\
UKTERM & 0.06 & 0.08 & 0.08 & 0.09 & 0.09 \\
\hline \multicolumn{5}{c}{ with USIPG } \\
JPIPG & 0.06 & 0.17 & 0.14 & 0.23 & 0.18 \\
GEIPG & 0.03 & 0.07 & 0.09 & 0.07 & 0.11 \\
UKIPG & 0.04 & 0.04 & 0.24 & 0.08 & 0.02 \\
\hline \multicolumn{5}{c}{ with } & USINF \\
JPINF & 0.18 & 0.36 & 0.32 & 0.28 & 0.29 \\
GEINF & 0.24 & 0.34 & 0.41 & 0.24 & 0.23 \\
UKINF & 0.37 & 0.39 & 0.36 & 0.37 & 0.40 \\
\hline \hline
\end{tabular}

Notes: The acronyms for countries are US for USA, JP for Japan, GE for Germany and UK for United Kingdom. RET refers to one month stock returns, TERM to the term premium between 5 years bonds and 3 months bills, AEG to one month changes in the US $\$$ dollar exchange rate, IPG to one month industrial production growth and INF to one month inflation rate. The sample is 1973:1-1993:12. The standard deviations for autocorrelations, under the null of no serial correlation is $\sqrt{\frac{1}{252}} \approx 0.062$. 
Table 2: Percentage of the 24 month Forecast Error Variance

Explained by Innovations in each Variable based on a 4 Variable VAR

Including Stock Returns (RET), Term Premiums (TERM)

Changes In Industrial Production (IPG) and Inflation Rate (INF)

\begin{tabular}{|c|c|c|c|}
\hline \multicolumn{4}{|c|}{ US Variables } \\
\hline \multirow[t]{2}{*}{ Innovations in } & \multicolumn{3}{|c|}{ Variance of } \\
\hline & \multicolumn{2}{|c|}{ RET TERM IPG } & INF \\
\hline RET & $93.6^{*}$ & 0.9 & 2.4 \\
\hline TERM & $79.7^{*}$ & 7.6 & $32.6^{*}$ \\
\hline IPG & $14.6^{*}$ & $90.4^{*}$ & $11.1^{*}$ \\
\hline INF & 0.9 & 0.4 & $52.9^{*}$ \\
\hline \multicolumn{4}{|c|}{ Japan Variables } \\
\hline \multirow[t]{2}{*}{ Innovations in } & \multicolumn{3}{|c|}{ Variance of } \\
\hline & \multicolumn{2}{|c|}{ RET TERM IPG } & INF \\
\hline$\overline{\mathrm{RET}}$ & $97.7^{*} \quad 1.7$ & 0.9 & 3.8 \\
\hline TERM & $0.3 \quad 93.4^{*}$ & 7.1 & 6.8 \\
\hline IPG & 0.7 & $90.4^{*}$ & 0.9 \\
\hline INF & 0.5 & 0.8 & $87.1^{*}$ \\
\hline \multicolumn{4}{|c|}{ German Variables } \\
\hline \multirow[t]{2}{*}{ Innovations in } & \multicolumn{3}{|c|}{ Variance of } \\
\hline & \multicolumn{2}{|c|}{ RET TERM IPG } & INF \\
\hline RET & $94.1^{*}$ & 0.6 & 0.8 \\
\hline TERM & $98.3^{*}$ & 1.2 & 6.4 \\
\hline IPG & 0.1 & $95.9^{*}$ & 0.4 \\
\hline INF & 0.4 & 1.8 & $91.5^{*}$ \\
\hline \multicolumn{4}{|c|}{ UK Variables } \\
\hline \multirow[t]{2}{*}{ Innovations in } & \multicolumn{3}{|c|}{ Variance of } \\
\hline & RET TERM & IPG & INF \\
\hline$\overline{\mathrm{RET}}$ & $97.9^{*}$ & 2.2 & 2.0 \\
\hline TERM & $0.497 .2^{*}$ & 0.9 & 4.5 \\
\hline IPG & 0.4 & $94.9^{*}$ & 1.1 \\
\hline INF & 0.4 & 1.4 & $91.2^{*}$ \\
\hline
\end{tabular}

Notes: RET refers to one month stock returns, TERM to the term premium between 5 years bonds and 3 months bills, AEG to one month changes in the US $\$$ dollar exchange rate, IPG to one month industrial production growth and INF to one month inflation rate. The sample is 1973:1-1993:12. The forecast error variance is computes using a 4 variable VAR model with a constant and one lag. The table shows the mean percentage of the 24 month forecast error variance in variable $\mathrm{i}$ explained by innovations in variable $\mathrm{j}$, computed as $\frac{1}{Q} \sum_{q=1}^{Q}\left\{100 *\left[\sum_{s=0}^{23} C_{s}^{i j} / \sum_{j=1}^{4} \sum_{s=0}^{23} C_{s}^{i j}\right\}\right.$, where $C_{s}^{i j}$ is obtained from the orthogonalized moving average representation of $\hat{y}_{t}=y_{t}-\mu_{0}=\sum_{s=0}^{\infty} C_{s} u_{t-s}$ where $\hat{y}_{t}$ is a $4 \times 1$ vector and $\mathrm{Q}$ is the number of Monte Carlo replications. $\mathrm{A}^{\text {'* }}$, indicates that the 5 th percentile of the distribution is above the $5 \%$ level. 
Table 3: Percentage of the 24 month Forecast Error Variance

Explained by Innovations in each Variable based on a 9 Variable VAR

Including Stock Returns (RET), Term Premiums (TERM), Changes in the Exchange Rate (AEG) Changes In Industrial Production (IPG) and Inflation Rate (INF)

\begin{tabular}{|c|c|c|c|c|c|c|c|c|c|}
\hline \multicolumn{10}{|c|}{ US and Germany Variables } \\
\hline \multirow[t]{2}{*}{ Innovations in } & \multicolumn{9}{|c|}{ Variance of } \\
\hline & \multicolumn{8}{|c|}{ USRET GERET USTERM GETERM GEAEG USIPG GEIPG USINF } & GEINF \\
\hline USRET & $83.2^{*}$ & 9.7 & 2.9 & 0.8 & 2.4 & 1.0 & 1.0 & 2.2 & 1.3 \\
\hline GERET & 2.4 & $80.1^{*}$ & 0.4 & 0.6 & 0.8 & 1.1 & 0.7 & 0.7 & 0.7 \\
\hline USTERM & 1.5 & 1.2 & $75.4^{*}$ & 3.8 & 1.6 & 6.4 & 1.1 & $30.7^{*}$ & $15.6^{*}$ \\
\hline GETERM & 0.6 & 0.5 & 1.1 & $86.4^{*}$ & 0.9 & 1.7 & 1.2 & 2.5 & 2.6 \\
\hline GEAEG & 0.5 & 0.7 & 2.8 & 2.3 & $89.3^{*}$ & 4.2 & 2.0 & 2.2 & 2.1 \\
\hline USIPG & 3.0 & 1.9 & 10.9 & 1.0 & 0.5 & $80.7^{*}$ & 1.1 & 9.3 & 4.3 \\
\hline GEIPG & 2.9 & 1.2 & 0.1 & 0.0 & 0.7 & 0.2 & $86.6^{*}$ & 0.5 & 0.7 \\
\hline USINF & 1.4 & 1.5 & 1.0 & 0.4 & 0.3 & 0.5 & 1.6 & $48.0^{*}$ & 3.9 \\
\hline GEINF & 1.6 & 1.8 & 1.3 & 0.5 & 1.8 & 0.7 & 2.4 & 2.1 & $65.7^{*}$ \\
\hline \multicolumn{10}{|c|}{ US and UK Variables } \\
\hline \multirow[t]{2}{*}{ Innovations in } & \multicolumn{9}{|c|}{ Variance of } \\
\hline & \multicolumn{8}{|c|}{ USRET UKRET USTERM UKTERM UKAEG USIPG UKIPG USINF } & UKINF \\
\hline USRET & $90.1^{*}$ & $22.2^{*}$ & 2.3 & 2.2 & 1.3 & 0.9 & 0.8 & 2.2 & 2.5 \\
\hline UKRET & 0.4 & $67.8^{*}$ & 0.8 & 1.9 & 1.1 & 1.3 & 1.7 & 1.3 & 1.1 \\
\hline USTERM & 1.3 & 1.0 & $72.1^{*}$ & 2.9 & 0.9 & $7.2^{*}$ & 1.2 & $28.6^{*}$ & $16.1^{*}$ \\
\hline UKTERM & 0.6 & 0.5 & 1.3 & $85.2^{*}$ & 3.8 & 0.9 & 0.7 & 2.3 & 4.4 \\
\hline UKAEG & 0.6 & 0.7 & 2.7 & 0.7 & $89.1^{*}$ & 4.0 & 1.2 & 2.0 & 1.3 \\
\hline USIPG & 2.0 & 2.7 & 11.7 & 0.8 & 0.9 & $81.2^{*}$ & 5.0 & 10.4 & 4.2 \\
\hline UKIPG & 0.8 & 1.2 & 1.5 & 0.4 & 0.3 & 0.7 & $85.3^{*}$ & 2.8 & 1.7 \\
\hline USINF & 1.0 & 0.9 & 1.3 & 0.3 & 0.2 & 0.4 & 0.6 & $44.7^{*}$ & 2.1 \\
\hline UKINF & 0.4 & 0.8 & 0.6 & 0.5 & 0.3 & 0.3 & 0.7 & 1.5 & $62.6^{*}$ \\
\hline \multicolumn{10}{|c|}{ US and Japan Variables } \\
\hline \multirow[t]{2}{*}{$\overline{\text { Innovations in }}$} & \multicolumn{9}{|c|}{ Variance of } \\
\hline & USRET & JPRET & USTERM & JPTERM & JPAEG & USIPG & JPIPG & USINF & JPINF \\
\hline USRET & $90.0^{*}$ & $15.2^{*}$ & 2.2 & 2.9 & 1.3 & 1.4 & 0.8 & 2.0 & 5.0 \\
\hline JPRET & 0.5 & $76.5^{*}$ & 3.8 & 4.2 & 5.1 & 3.0 & 0.9 & 2.5 & 2.7 \\
\hline USTERM & 1.2 & 0.8 & $68.5^{*}$ & 18.7 & 3.7 & 8.9 & 2.0 & 27.7 & 12.2 \\
\hline JPTERM & 0.7 & 0.3 & 5.1 & $62.7^{*}$ & 1.3 & 2.5 & 5.1 & 2.0 & 2.8 \\
\hline JPAEG & 0.6 & 0.9 & 3.4 & 4.0 & $85.3^{*}$ & 1.9 & 1.1 & 2.2 & 1.3 \\
\hline USIPG & 2.3 & 1.1 & 12.7 & 2.9 & 0.8 & $77.9^{*}$ & 4.5 & 10.5 & 3.6 \\
\hline JPIPG & 0.9 & 0.5 & 0.1 & 0.3 & 0.2 & 0.8 & $82.1^{*}$ & 0.5 & 0.7 \\
\hline USINF & 1.6 & 1.6 & 0.8 & 0.6 & 0.2 & 0.5 & 0.8 & $45.6^{*}$ & 1.8 \\
\hline JPINF & 0.5 & 0.4 & 0.3 & 1.2 & 0.4 & 0.4 & 0.8 & 3.1 & $68.1^{*}$ \\
\hline
\end{tabular}

Notes: The acronyms for countries are US for USA, JP for Japan, GE for Germany and UK for United Kingdom. RET refers to one month stock returns, TERM to the term premium between 5 years bonds and 3 months bills, AEG to one month changes in the US $\$$ dollar exchange rate, IPG to one month industrial production growth and INF to one month inflation rate. The sample is 1973:11993:12. Forecast error variance is computes using a 9 variable VAR model with a constant and one lag. The table shows the mean percentage of the 24 month forecast error variance in variable $\mathrm{i}$ explained by innovations in variable $\mathrm{j}$, computed as $\frac{1}{Q} \sum_{q=1}^{Q}\left\{100 *\left[\sum_{s=0}^{23} C_{s}^{i j} / \sum_{j=1}^{9} \sum_{s=0}^{23} C_{s}^{i j}\right\}\right.$ where $C_{s}^{i j}$ is obtained from the orthogonalized moving average representation of $\hat{y}_{t}=y_{t}-\mu_{0}=$ $\sum_{s=0}^{\infty} C_{s} u_{t-s}$ where $\hat{y}_{t}$ is a $9 \times 1$ vector and $Q$ is the number of Monte Carlo replications. A "*, indicates that the 5 th percentile of the distribution is above the $5 \%$ level. 